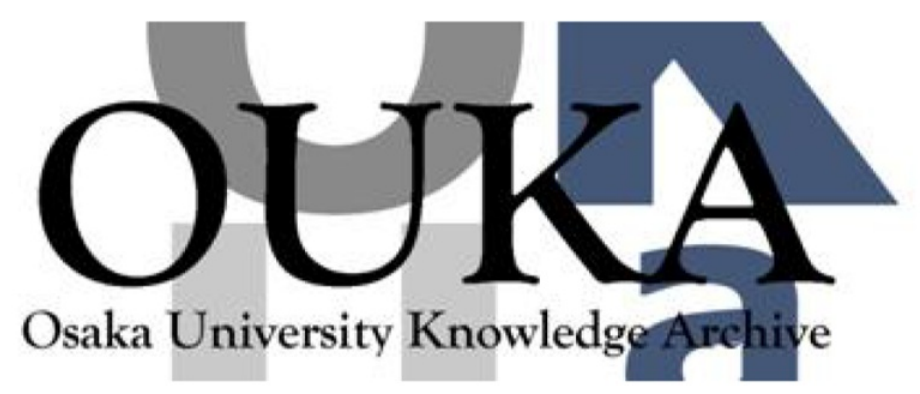

\begin{tabular}{|c|l|}
\hline Title & $\begin{array}{l}\text { Diagnostic technique to assess the condition of } \\
\text { stator insulation by measuring microwave } \\
\text { associated with dielectric breakdown }\end{array}$ \\
\hline Author(s) & $\begin{array}{l}\text { Kawada, Masatake; Kawasaki, Zen-ichiro; } \\
\text { Matsuura, Kenji }\end{array}$ \\
\hline Citation & $\begin{array}{l}\text { Conference Record of IEEE International } \\
\text { Symposium on Electrical Insulation. 1 p. 249- } \\
\text { p. 252 }\end{array}$ \\
\hline Issue Date & $1998-06$ \\
\hline oaire:version & VoR \\
\hline URL & $\begin{array}{l}\text { https://hdl.handle. net/11094/14097 } \\
\text { c1998 IEEE. Personal use of this material is } \\
\text { permitted. However, permission to } \\
\text { reprint/republish this material for advertising } \\
\text { or promotional purposes or for creating new } \\
\text { collective works for resale or redistribution } \\
\text { to servers or lists, or to reuse any } \\
\text { copyrighted component of this work in other } \\
\text { works must be obtained from the IEEE.. }\end{array}$ \\
\hline rights \\
\hline Note & \begin{tabular}{l} 
\\
\hline
\end{tabular} \\
\hline
\end{tabular}

Osaka University Knowledge Archive : OUKA

https://ir. Library. osaka-u. ac. jp/

Osaka University 
Conference Record of the 1998 IEEE International Symposium on Electrical Insulation, Arlington, Virginia, USA, June 7-10, 1998

\title{
Diagnostic Technique to Assess the Condition of Stator Insulation by Measuring Microwave Associated with Dielectric Breakdown
}

\author{
Masatake Kawada, Zen-Ichiro Kawasaki, Kenji Matsuura \\ kawada@pels.pwr.eng.osaka-u.ac.jp \\ Matsuura Lab.,Department of Electrical Engineering, Faculty of Engineering, \\ Osaka University, Yamadaoka 2-1, Suita, 565-0871 Japan
}

\begin{abstract}
Partial Discharge (PD) occurring in the stator insulation of the generator is a symptom and/or a direct cause of the deterioration of the insulation system. It is reported that PD is a very short duration current and/or voltage pulse, about $1 \sim 5$ [ns]. Generally PD emits electromagnetic waves which are broadband signals ( $\sim \mathrm{GH} z$ ). Therefore wo developed a new system for detecting the electromagnetic waves, especially microwave (GHz) emitted from. From the point of viow of protecting an accident caused by the insulation breakdown, it is important to assess the condition of the winding. We applied our system to a dielectric breakdown test to know the relation between the characteristios of the microwave and the insulation condition of the winding. The dielectric breakdown test is useful for estimating the minimum breakdown voltage which is a criterion of the insulation condition of the winding. Experimental results showed that this system was able to assess the insulation condition by measuring the number of the pulses of the microwave per voltage cycle.
\end{abstract}

\section{INTRODUCTION}

Partial Discharge (PD) occurring in the insulation of the stator windings of the generator is a symptom and/or a direct cause of the deterioration of the insulation system. It's reported that $P D$ is a very short phenomenon. Generally PD emits electromagnetic waves and the bandwidth of the electromagnetic waves is very broad and ranges to $\mathrm{GHz}$. Therefore we have developed a new system for detecting the electromagnetic waves, especially microwave ( $\mathrm{GHz}$ ) emitted from $\mathrm{PD}$ due to a material defect of the stator winding.

The plant maintenance engineer simply wants to predict the remaining life of the stator winding. This allows him/her to remove the generator from service at a convenient time just before failure, in order to maximize the capital investment in the old winding, yet avoid any consequential costs of having an in-service failure. From the point of view of avoiding an accident caused by the insulation breakdown, it's important to assess the condition of the stator insulation and the residual-life of the winding, that is, to decide when the operation of the generator should be stopped. A destructive test ,that is, a dielectric breakdown test, has been done to assess the minimum breakdown voltage which is a criterion of the condition of the insulation. The cumulative counts of the dielectric breakdown[\%] based on the normal distribution function obtained from the dielectric breakdown test is generally used as an index of the condition of the insulation.

Then we applied our system to the dielectric breakdown test to relate the characteristics of the microwave emitted from PD with the condition of the insulation. We monitored PD activity by receiving the microwave, when the applied voltage was raised gradually until the insulation punctured We had an eye to the number of the pulses of the microwave per voltage cycle $(60[\mathrm{~Hz})$ to assess the condition of the insulation. Experimental results showed that this diagnostic technique, by receiving the microwave, was able to assess the condition of the insulation of the winding.

\section{MEASUREMENT SYSTEM [1]}

Figure1 shows the measurement system to receive and to analyze the microwave emitted from $P D$. The microwave is received with the double-ridge-guidehorn-antenna, and the signal is passed through the preamplifier, and then inputted into the downconverter. The signal outputted from the downconverter is inputted into the personal computer using the $\mathrm{A} / \mathrm{D}$ converter (sampling frequency: $1[\mathrm{MHz}$ ). The trigger signal which starts the $\mathrm{AD}$ converter is 
generated when the value of the applied voltage is 0 , i.e., zero-cross of the applied voltage.

Figure2 shows the diagram of GHz-2chdown-converter (GHz-interference-type-receiver). The center frequency of the built-in local generator of the down-converter can be tuned from $2[\mathrm{GHz}]$ to $3[\mathrm{GHz}]$ at the intervals of $100[\mathrm{MHz}]$ voluntarily. The center frequency of the input-signal is down-converted by mixing the input-signal and the signal generated by the built-in local generator, given as Equation(1),

$$
f_{\text {out }}=\left|f_{\text {tn }}-f_{\text {local }}\right|
$$

where $f_{\text {out }}$ is the center frequency of the output signal of the down-onverter, fin is the center frequency of the input signal, flooal is the center frequency of the signal generated by the built-in local generator, respectively. The center frequency of the input-signal can be downconverted without changing the distribution of the frequency spectrum of them.

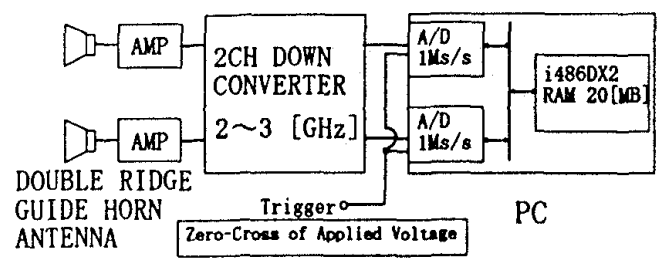

Fig.1 Measurement system of the microwave

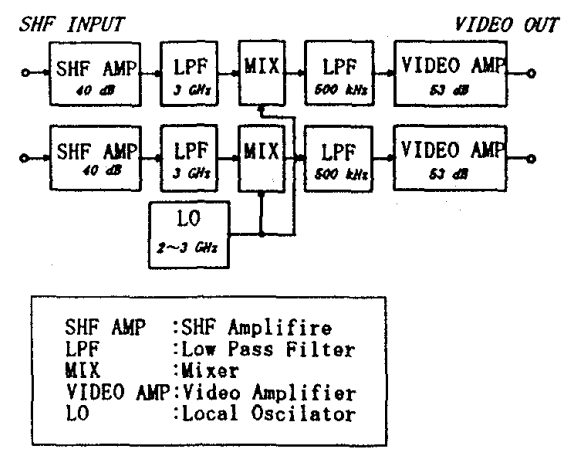

Fig.2 Block diagram of $\mathrm{GHz} 2 \mathrm{ch}$ down converter

\section{DIELECTRIC BREAKDOWN TEST}

The dielectric breakdown test has been done to assess the minimum breakdown voltage of the insulation. We did the dielectric breakdown test for 4 stator coils taken from the turbine generator when the generator was rewound Table1 shows the specification of the generator. Figure3 shows the circuit of the dielectric breakdown test and the breakdown point of the stator coil The dielectric breakdown test using this circuit can puncture the only insulation in contact with
Table1 The specification of the turbine generator

\begin{tabular}{|ll|}
\hline Rating & $: 156[\mathrm{MVA}], 18[\mathrm{kV}]$, \\
& $3600[\mathrm{rpm}]$ \\
Operating Time & $: 145,578[\mathrm{~h}]$ \\
Start-Stop & $: 810[$ counts] \\
Insulation System & Polyester resin
\end{tabular}

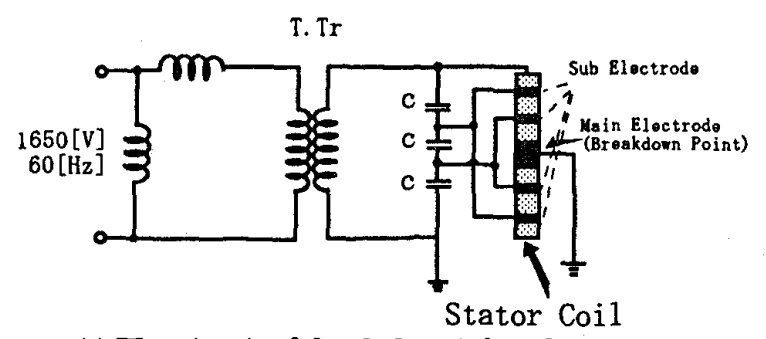

(a) The circuit of the dielectric breakdown test

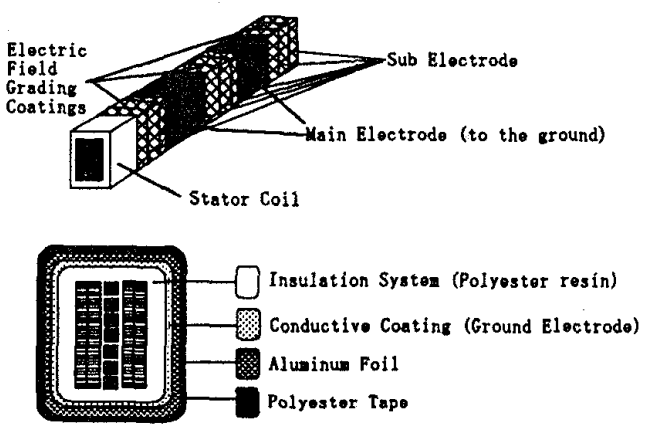

Cross Section of Main Electrode

(b) The structure of the electrode

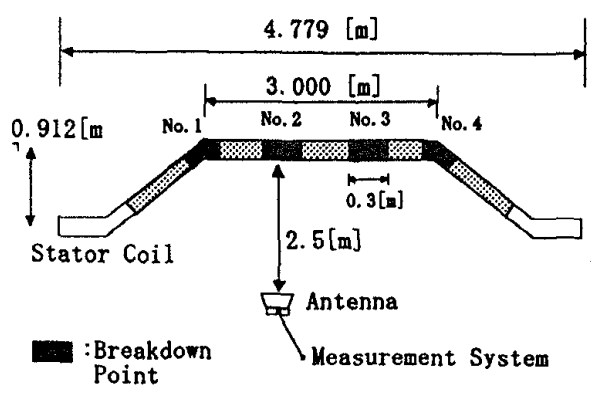

(c) The breakdown point of the winding

Fig. 3 The circuit of the dielectric breakdown test and the breakdown point of the winding

the main electrode which is grounded. We tried to prevent the flashover on the surface of the coil and to reduce the electromagnetic noise by applying the electric field grading coatings between the electrodes on the surface. We applied A.C. voltage (60[Hz]) to the coil, with the voltage raised from $40[\mathrm{kV}]$ in $5[\mathrm{kV}](\mathrm{Vr} . \mathrm{m} . \mathrm{s})$ increments for every 1 [min] until the breakdown occurred, that is, until the insulation punctured. We did the breakdown test for four coils and measured the 
microwave three points of the only one coil among them. We broke down four points for every coil and the total number of the points for the four coils were 15 , because one point was failed to measure. We measured the microwave emitted from the point in contact with the main electrode, with the voltage applied under $70[\mathrm{kV}]$, because the breakdown voltage was estimated to be about from $54[\mathrm{kV}]$ to $72[\mathrm{kV}]$ which was about from three to four times of the rating of the coil, that is, 3 $4 \times 18[\mathrm{kV}]$.

As the index is needed to assess the condition of the insulation, the cumulative counts of dielectric breakdown is used in this paper. Figure4 shows the relationship between the breakdown voltage and the cumulative counts of dielectric breakdown. The distribution of the breakdown voltage is almost the normal distribution because the relation is linear on the probability plot as shown in Fig.4. Then we used the cumulative counts of dielectric breakdown[\%] based on the normal distribution function obtained from the Equation(2) as the index of the condition of the insulation. The minimum breakdown voltage can be estimated by ( Mean Value - $3 \times$ Standard Deviation ) of 3 Standard Deviation Method on JS (Japanese Industrial Standard), that is, $59.52[\mathrm{kV}](=75.27[\mathrm{kV}]$ $3 \times 5.25[\mathrm{kV}]$ ). We considered the minimum breakdown voltage $59[\mathrm{kV}]$ as the index to stop the operation of the generator.

$$
\begin{aligned}
& f(V)=\frac{1}{\sqrt{2 \pi \sigma^{2}}} \exp \left(-\frac{(V-\bar{V})^{2}}{2 \sigma^{2}}\right) \times 100[\%] \\
& F(V)=\sum_{0}^{V} f(V) \\
& f(V): \text { Counts of Dielectric Breakdown [\%] } \\
& F(V): \text { Cumulative Counts of Dielectric Breakdown }[\%] \\
& V \quad: \text { Applied Voltage }[\mathrm{kV}] \\
& \bar{V} \quad: \text { Average of BreakdowVoltage }[\mathrm{kV}](=75.27[\mathrm{kV}]) \\
& \sigma \quad: \text { Standard Deviation }[\mathrm{kV}](=5.25[\mathrm{kV}])
\end{aligned}
$$

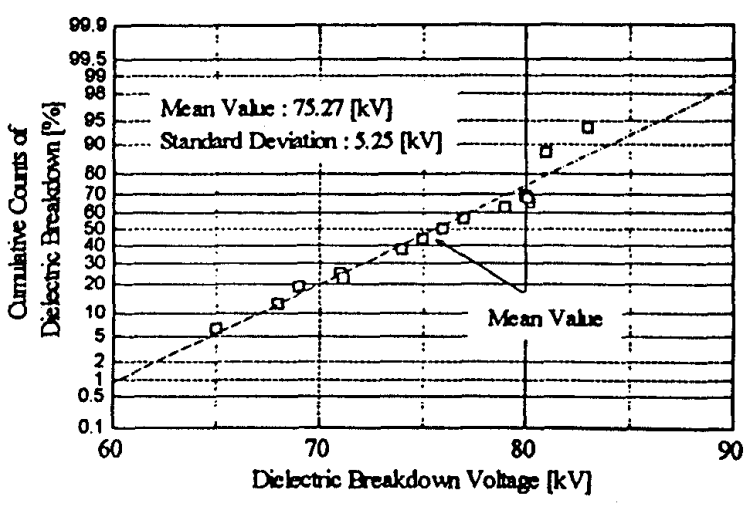

Fig.4 The relationship between the breakdown voltage and the cumulative counts of the dielectric breakdown

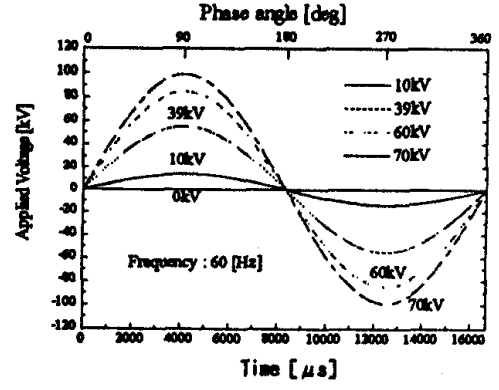

(a) Applied Voltage (Vr.m.s)

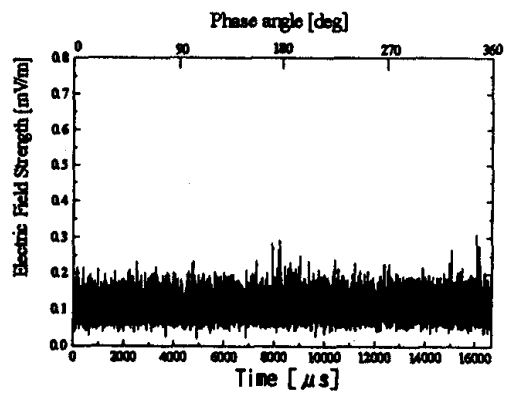

(b) $10[\mathrm{kV}]$

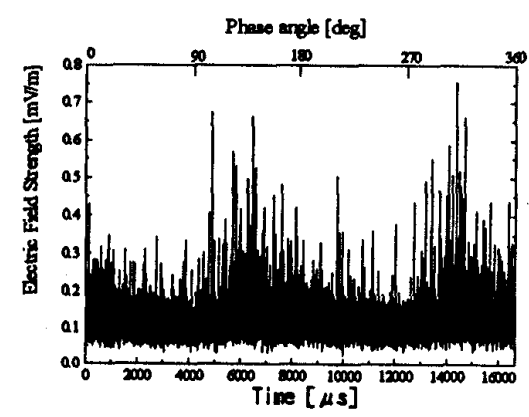

(c) $60[\mathrm{kV}]$

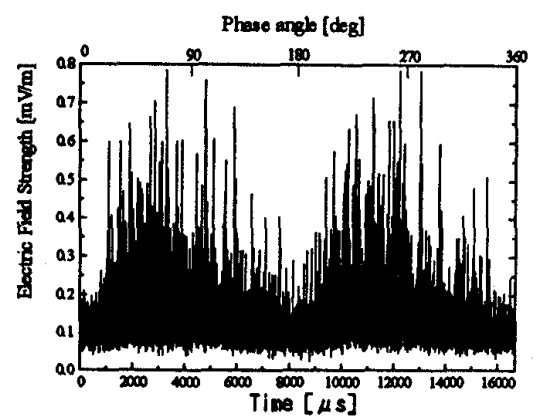

(d) $70[\mathrm{kV}]$

Fig.5 Received microwave at the each applied voltage 


\section{INSULATION DIAGNOSTIC METHOD BY MEASURING MICROWAVE}

Figure5 shows the received microwave at each applied voltage. The number of pulses of the microwave increased and the magnitude became larger with the applied voltage raised from $0[\mathrm{kV}]$ to $80[\mathrm{kV}]$ (Vr.m.s) : the breakdown voltage of the winding. The phase angle of the maximum of the electric field strength shifted gradually from 0 (360 [degD), 180[deg] to $20-90,200-$ $270[\mathrm{deg}]$. We had an eye to the number of pulses of the microwave per voltage cycle $(60[\mathrm{HzD}$ to assess the condition of the insulation. Figure6 shows the histogram of pulse count difference between the microwave and the background noise. The total number of the pulses was clearly increased with the applied voltage raised from 0 to $70[\mathrm{kV}]$. The rate of increase of the total pulses from $60[\mathrm{kV}]$ to $70[\mathrm{kV}]$ was high, compared with the increase from 0 to $60[\mathrm{kV}]$. Therefore the number of pulses of the microwave was rapidly increasing as the insulation was breaking down.

Figure7 shows the relationship between the total number of pulses of the microwave and the cumulative counts of the dielectric breakdown based on the normal distribution function obtained from the Equation(2), because the condition of the insulation is generally assessed by the cumulative counts of the dielectric breakdown, not by the applied voltage. The data was obtained from three breakdown points, no.2, no. 3 and no. 4 of one stator coil The number of pulses is a relative index because it depends on the classification of the histogram of the pulses of the microwave. The cumulative counts of the dielectric breakdown [\%] is increasing with the total number of the pulses. For example, the cumulative counts of the dielectric breakdown is 0.008 [\%] at 60 [counts], and 18.131 [\%] at

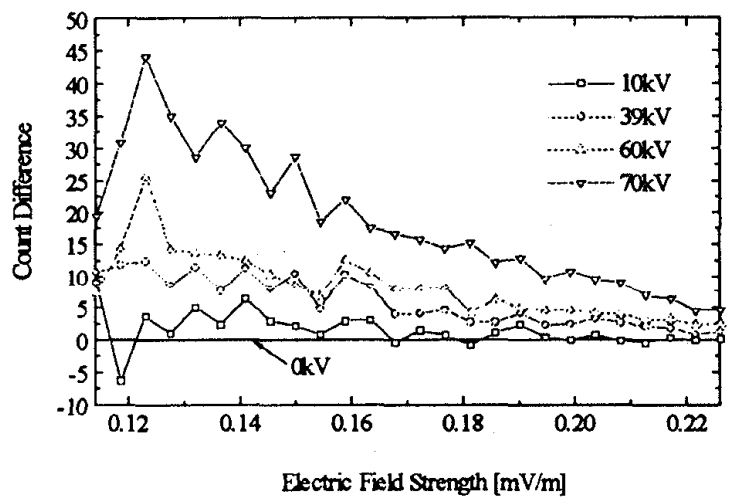

Fig.6 The histogram of the pulse count difference between the microwave and the background noise

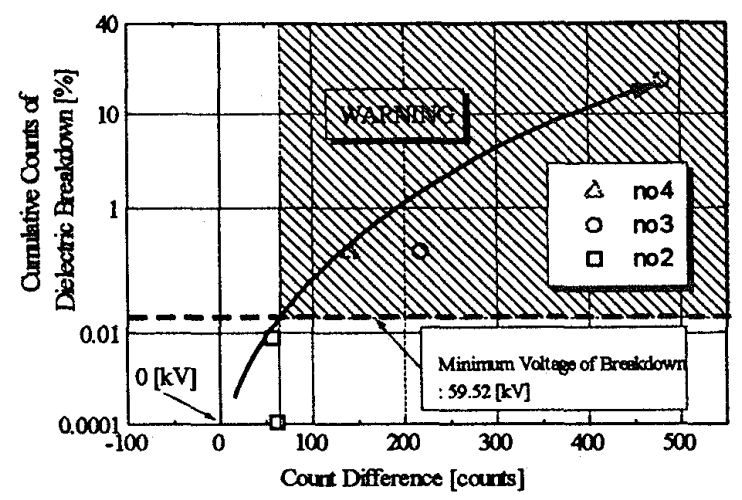

Fig.7 Insulation diagnosis by the counts of the microwave

480 [counts] respectively. We can judge the condition of the insulation to be in danger if the number of pulses is more than about 70 [counts], because the minimum voltage of breakdown of the three stator coils is $59.52[\mathrm{kV}]$. Therefore we can prevent the accident caused by the insulation breakdown.

\section{CONCLUSION}

From the point of view of avoiding an accident caused by the insulation breakdown, we applied our system to the dielectric breakdown test of the stator coil The number of pulses of the microwave increased with the applied voltage raised. The phase angle of the maximum of the electric field strength shifted gradually from 0 (360 [degD, 180[deg] to 20-90,200-270[deg] for the applied voltage.

We can assess the condition of the stator insulation by relating the total number of pulses of the microwave with the cumulative counts of dielectric breakdown [\%] based on the normal distribution function obtained from the dielectric breakdown test.

\section{ACKNOWLEDGMENT}

The authors wish to thank Kansai Electric Power Co. INC. and Mitsubishi Electric Corporation for their valuable discussions.

\section{REFERENCES}

[1] M.Kawada et al,"Development of a New System for Detecting Microwave Associated with a Partial Discharge of the Stator Coil in Generator using Spatial Phase Difference Method", T.IEEJ, Vol117-B,No.2, 1997 